\title{
Transscleral Cyclophotocoagulation in Familial Amyloidotic Polyneuropathy Secondary Glaucoma after Ahmed Valve Implantation: A Case Series Study
}

\author{
Rita Vieira ${ }^{1}$, Ana Marta ${ }^{2}$, Ana Figueiredo $^{3}$, Rita Reis ${ }^{4}$, Isabel Sampaio ${ }^{5}$, Maria J Menéres ${ }^{6}$
}

\begin{abstract}
Purpose: To investigate the outcomes of transscleral cyclophotocoagulation (TSCPC) after Ahmed glaucoma valve (AGV) implantation failure in patients with familial amyloidotic polyneuropathy (FAP) secondary glaucoma.

Materials and methods: In this retrospective study, all patients with secondary FAP glaucoma who underwent AGV implantation between 2010 and 2019 in our tertiary center were assessed. Among all, those patients who needed TSCPC to control intraocular pressure (IOP) after AGV were selected. Demographic data, value of IOP, best-corrected visual acuity (BCVA), number of antiglaucomatous medications, surgical complications, and need for retreatment were collected.

Results: From a total of 124 eyes submitted to AGV implantation, 13 eyes (10.48\%) needed TSCPC to control IOP. The median age at TSCPC was 49.50 years $(43 ; 55.75)$, and the median period between AGV implantation and TSCPC was 1.63 years $(1.00 ; 3.65)$. There was a significant decrease of IOP after the procedure, from $24.33 \pm 4.76$ to $11.33 \pm 2.90 \mathrm{~mm} \mathrm{Hg}$ at last visit $(p<0.001)$. A reduction in the number of antiglaucomatous medications was also noticed, from $3.92 \pm 0.29$ to $1.25 \pm 1.42(p<0.001)$. There was no difference in BCVA $(p=0.502)$. After the procedure, there was an exuberant anterior chamber (AC) reaction in two eyes (16.7\%), and one case developed a neurotrophic ulcer ( $8.3 \%)$. There was no need for re-treatment.
\end{abstract}

Conclusion: Ahmed glaucoma valve implantation is a promising surgical procedure to treat patients with PAF secondary glaucoma, showing good results. For refractory cases, TSCPC seems to be effective and safe to control IOP.

Clinical significance: There are only a few studies in current literature that address amyloid secondary glaucoma, maybe because it is a rare pathology worldwide. However, it has a high incidence in certain regions, including the north of Portugal. For the record, this is the first study describing the tool of cycloablative procedures in this type of glaucoma.

Keywords: Ahmed valve implantation, Case series, Familial amyloidotic polyneuropathy, Secondary glaucoma, Transscleral cyclophotocoagulation. Journal of Current Glaucoma Practice (2021): 10.5005/jp-journals-10078-1296

\section{INTRODUCTION}

Familial amyloidotic polyneuropathy (FAP) is a rare hereditary disease caused by mutations in the gene encoding transthyretin, a protein mainly produced by the liver. This condition presents as an adult-onset, autosomal dominant disease with variable penetrance. The most common form of ATTR variant in Portugal, as in the world, is the Val30Met mutation. Portugal, where the disease was first described, is one of the three major endemic clusters for ATTR amyloidosis, along with Sweden, and Japan. Nevertheless, with the advent of migration, it can be found worldwide. The disease is characterized by a multisystemic extracellular deposition of amyloid fibrils, leading to dysfunction of different organs and tissues including the peripheral nerves, heart, kidney, ocular tissues, and others. ${ }^{1-3}$

Ocular involvement is a prominent feature of FAP and is related to amyloid deposition within ocular tissues, predominantly in the vitreous body, conjunctiva, trabecular meshwork, anterior capsule of the lens, iris, and pupil borders, with numerous patients showing scalloped iris. ${ }^{4}$ Vision-threatening conditions, such as glaucoma, are not rare in patients with FAP, especially because liver transplant elongates life expectancy, which increases the probability of ocular complications to occur. ${ }^{5}$ Although the liver is the major site of TTR production, it is also produced locally in the eye by the retinal pigment epithelium (RPE) and ciliary pigment epithelium, which justifies the higher prevalence of glaucoma in these patients

\footnotetext{
${ }^{1-5}$ Ophthalmology Department of Centro Hospitalar Universitário do Porto (CHUP), Oporto, Portugal

${ }^{6}$ Ophthalmology Department of Centro Hospitalar Universitário do Porto (CHUP), Oporto, Portugal; Instituto de Ciências Biomédicas Abel Salazar (ICBAS), Oporto, Portugal
}

Corresponding Author: Rita Vieira, Ophthalmology Department of Centro Hospitalar Universitário do Porto (CHUP), Oporto, Portugal, Phone: +351 913748812, e-mail: anarita.vieira1693@gmail.com

How to cite this article:Vieira R, Marta A, Figueiredo A, et al. Transscleral Cyclophotocoagulation in Familial Amyloidotic Polyneuropathy Secondary Glaucoma after Ahmed Valve Implantation: A Case Series Study. J Curr Glaucoma Pract 2021;15(1):32-35.

Source of support: Nil

Conflict of interest: None

and the need for a better understanding of the disease and its management. $^{5-7}$

Familial amyloidotic polyneuropathy secondary glaucoma usually has an accelerated course and often needs surgical intervention. Beirão et al. referred that a more aggressive progression may be related to the decrease of neuroprotective endocular factors such as erythropoietin, which has increased production in the aqueous humor in other glaucoma types. ${ }^{8}$ Published literature reports trabeculectomy and deep sclerectomy

(c) Jaypee Brothers Medical Publishers. 2021 Open Access This article is distributed under the terms of the Creative Commons Attribution 4.0 International License (https://creativecommons.org/licenses/by-nc/4.0/), which permits unrestricted use, distribution, and non-commercial reproduction in anymedium, provided you give appropriate credit to the original author(s) and the source, provide a link to the Creative Commons license, and indicate if changes were made. The Creative Commons Public Domain Dedication waiver (http://creativecommons.org/publicdomain/zero/1.0/) applies to the data made available in this article, unless otherwise stated. 
as the most common surgical procedures performed in cases of uncontrolled intraocular pressure (IOP)..$^{9,10}$ On the other hand, aqueous humor drainage devices, such as Ahmed valve, have assumed an important role in cases of refractory glaucoma, either as a primary procedure or as a secondary procedure. ${ }^{11}$ One previous study, conducted in our department that studied outcomes of Ahmed glaucoma valve (AGV) implantation in PAF secondary glaucoma, showed that AGV implantation is a safe and effective option in these patients. ${ }^{12}$

Transscleral cyclophotocoagulation (TSCPC) has been classically used for the treatment of refractory glaucoma, including eyes in which other surgical treatments have failed and eyes with poor visual acuity. Nowadays, this procedure is executed in numerous types of glaucoma and in eyes with an initial better prognosis. A better understanding of the procedure led glaucoma experts to improve the technique to have fewer complications. These measures include the use of lower levels of energy and applying transillumination, which makes the ciliary body easier to identify. Thus, TSCPC is a practical, rapid, well-tolerated, and unexpensive procedure that provides lowering of IOP. ${ }^{13,14}$

\section{Materials and Methods}

In this retrospective study, all patients with secondary FAP glaucoma who underwent AGV implantation between 2010 and 2019 at the Ophthalmology Department of CHUP were assessed. Patients who underwent TSCPC to control IOP despite antiglaucomatous medication were included in this review. This study was conducted in accordance with the tenets of the Declaration of Helsinki (1964).

We assessed all demographic data, such as gender, age of diagnosis and onset of FAP's symptoms, the need for liver transplant and age of its occurrence, age at TSCPC, and the period between AGV implantation and TSCPC. Other ocular-related abnormalities were searched, such as the presence of vitreous amyloidosis or previous pars plana vitrectomy (PPV), retinal angiopathy, presence of amyloid in the anterior lens capsule and around pupil borders (scalloped iris). Data concerning AGV implantation, such as type of surgery (Ahmed valve implantation alone or combined with phacoemulsification, placement of the tube in the anterior or posterior chamber) and surgical complications were analyzed. Hypotony was defined as IOP $\leq 5 \mathrm{~mm} \mathrm{Hg}$ on two consecutive visits and a hypertensive phase was defined as the presence of an IOP $\geq 22 \mathrm{~mm} \mathrm{Hg}$ in any visit during the first 3 months.

In respect to TSCPC, IOP was measured by Goldmann applanation tonometry: at baseline, at the first day, at the 1st, 3rd, and 6th months after TSCPC, and at the last visit. The number of antiglaucomatous medications and best-corrected visual acuity (BCVA) in logMAR at baseline and at the final follow-up visit was also compared. A minimum follow-up of 6 months was considered. The need for retreatment and surgical complications were also collected. Surgical success was defined as IOP $>6$ and $\leq 21 \mathrm{~mm} \mathrm{Hg}$ with or without medication, and presence of light perception at the last evaluation; an absolute surgical success included the cases that did not require medication for IOP control.

Statistical analysis was performed with the SPSS $^{\oplus}$ statistics program (SPSS Statistics, version 25.0 for Windows, SPSS Inc., IBM, Somers, NY, USA). The variables' normality was tested by ShapiroWilk test, revealing non-significant results. Categorical variables are presented as frequencies and percentages, while continuous variables with medians and interquartile ranges. All statistical analysis was performed with nonparametric tests. A two-sided $p$ value $<0.05$ was considered statistically significant.

\section{Results}

From a total of 124 eyes with FAP secondary glaucoma submitted to Ahmed valve implantation, 13 eyes (10.48\%) from 12 patients underwent subsequent TSCPC to control IOP. Among these, only 12 cases ( 12 eyes from 11 patients) met inclusion criteria and 1 was excluded due to insufficient follow-up. All demographic data and FAP systemic and ocular features were collected. A resume of all collected data is presented in Table 1. Five patients were females

Table 1: Resume of collected data

\begin{tabular}{|c|c|}
\hline \multicolumn{2}{|l|}{ Demographic data } \\
\hline Number of patients; number of eyes & $\begin{array}{l}n=11 \text { patients; } n=12 \\
\text { eyes }\end{array}$ \\
\hline Gender & $\begin{array}{l}5 \text { female }(45.5 \%) ; 6 \text { male } \\
(54.5 \%)\end{array}$ \\
\hline Age of diagnosis & 23.0 years $(21.25 ; 29.75)$ \\
\hline Age of onset of symptomatic disease & 30 years $(22.75 ; 35.0)$ \\
\hline Age of liver transplant & 34.50 years $(27.25 ; 36.75)$ \\
\hline $\begin{array}{l}\text { Period between AGV implantation } \\
\text { and TSCPC }\end{array}$ & 1.63 years $(1.0 ; 3.65)$ \\
\hline Age of TSCPC & 49.50 years $(43.0 ; 55.75)$ \\
\hline \multicolumn{2}{|l|}{ Other ocular manifestations } \\
\hline Scalloped iris & $n=4(33.3 \%)$ \\
\hline Amyloid deposition on AL capsule & $n=1(8.3 \%)$ \\
\hline Vitreous amyloidosis/previous PPV & $n=9(75.0 \%)$ \\
\hline Retinal amyloid angiopathy & $n=7(58.3 \%)$ \\
\hline \multicolumn{2}{|l|}{ AGV implantation } \\
\hline $\begin{array}{l}\text { AGV implantation alone/combined } \\
\text { with phacoemulsification }\end{array}$ & $\begin{array}{l}n=8(66.7 \%) ; n=4 \\
(33.3 \%)\end{array}$ \\
\hline \multirow[t]{2}{*}{ Tube placement } & $\begin{array}{l}\text { AC: } n=11(91.7 \%) ; \mathrm{PC}: \\
n=1(8.3 \%)\end{array}$ \\
\hline & $\begin{array}{l}\text { Replacement from AC to } \\
\text { PC: } n=2(16.7 \%)\end{array}$ \\
\hline \multirow[t]{3}{*}{ Surgical complications } & $\begin{array}{l}\text { Hypertensive phase: } n=9 \\
(75.0 \%)\end{array}$ \\
\hline & $\begin{array}{l}\text { Hypotony with athalamia: } \\
n=1(8.3 \%)\end{array}$ \\
\hline & Cystic bleb: $n=1(8.3 \%)$ \\
\hline Previous glaucoma surgeries & $\begin{array}{l}\text { Trabeculectomy: } n=2 \\
(16.7 \%)\end{array}$ \\
\hline \multirow[t]{2}{*}{ Phakic status } & $\begin{array}{l}\text { Pseudophakic: } n=3 \\
(25.0 \%)\end{array}$ \\
\hline & Phakic: $n=9$ (75.0\%) \\
\hline \multicolumn{2}{|c|}{ Transscleral cyclophotocoagulation after AGV } \\
\hline \multirow[t]{2}{*}{$\mathrm{IOP}(\mathrm{mm} \mathrm{Hg})($ mean $\pm \mathrm{SD})$} & Baseline: $24.33 \pm 4.76$ \\
\hline & Last visit: $11.33 \pm 2.90$ \\
\hline \multirow{2}{*}{$\begin{array}{l}\text { Number of antiglaucomatous } \\
\text { medications (mean } \pm \text { SD) }\end{array}$} & Baseline: $3.92 \pm 0.29$ \\
\hline & Last visit: $1.25 \pm 1.42$ \\
\hline \multirow[t]{2}{*}{ LogMAR BCVA (mean \pm SD) } & Baseline: $0.34 \pm 0.19$ \\
\hline & Last visit: $0.39 \pm 0.30$ \\
\hline
\end{tabular}

AGV, Ahmed glaucoma valve; TSCPC, transscleral cyclophotocoagulation; $\mathrm{AL}$, anterior lens; $\mathrm{AC}$, anterior chamber; $\mathrm{PC}$, posterior chamber; $\mathrm{SD}$, standard deviation 

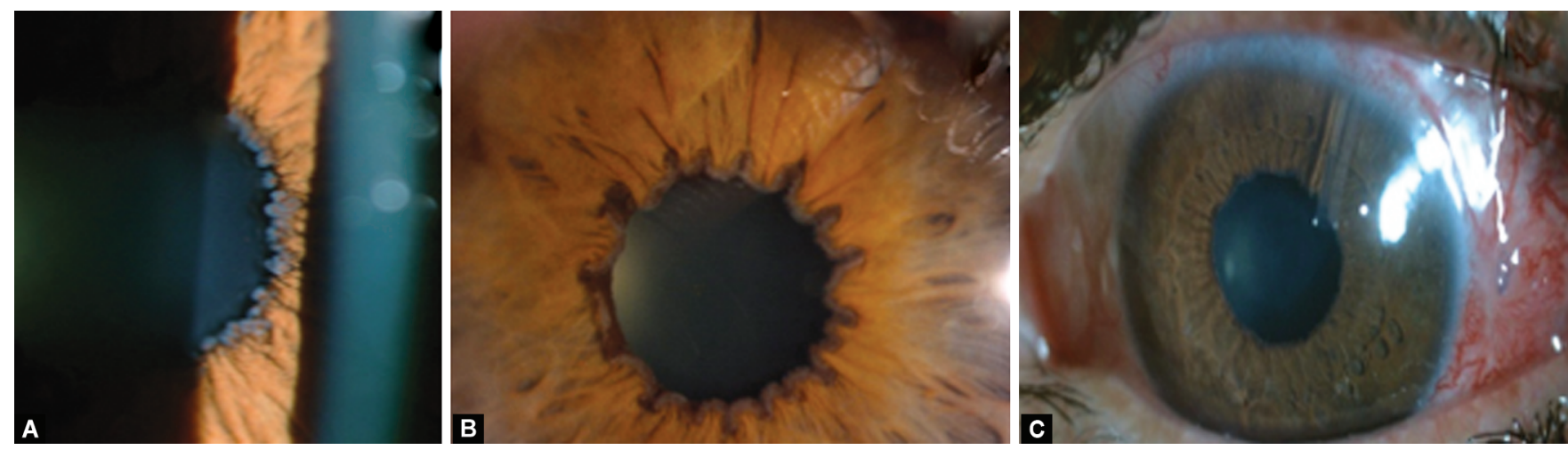

Figs 1 A to C: Ocular manifestations of FAP. (A) Amyloid deposition on the pupil border; (B) Scalloped iris or fringed pupil; (C) Valvular tube is placed on the AC; amyloid deposition on the anterior lens capsule. Images captured at the Ophthalmology Department of CHUP

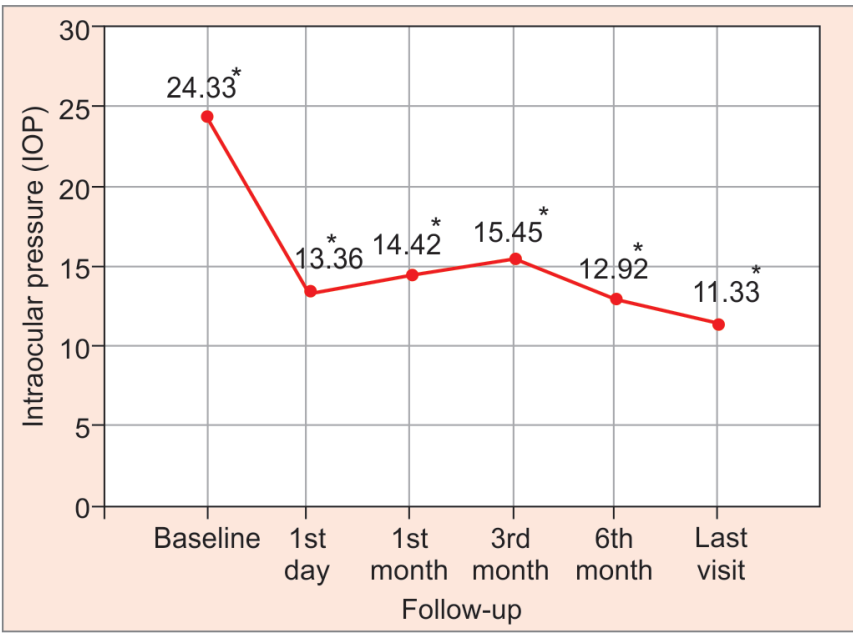

Fig. 2: IOP evolution during follow-up. $\left(^{*}\right)$ values show statistical significance, compared to baseline

(45.45\%) and six were males (54.55\%). Systemic PAF's symptoms appeared at the age of 30 years $(22.75 ; 35)$; almost all patients presented early onset of systemic symptoms (before 40 years old), and all underwent liver transplantation at a median age of 34.50 years $(27.25 ; 36.75)$. All patients had been submitted to pacemaker implantation.

Other ocular manifestations were investigated: nine patients (75.0\%) presented vitreous amyloidosis and underwent previous PPV; amyloidotic retinal angiopathy was present in seven eyes (58.3\%), four eyes (33.3\%) had scalloped iris, and one (8.3\%) presented amyloid deposition on the anterior lens capsule. Figure 1 shows images of ocular manifestations of FAP, captured in our department.

Ahmed valve implantation surgery was performed isolated in 8 eyes (66.7\%) and combined with phacoemulsification in 4 eyes (33.3\%); at surgery time, 3 eyes were pseudophakic (25.0\%) and 9 were phakic $(75.0 \%)$; the valvular tube was placed on the AC in 11 cases (91.76\%) and in one case on the posterior chamber (PC). The latter is preferably used in order to protect the corneal endothelium, except in phakic patients, which is placed on the AC. During follow-up, two cases (16.7\%) underwent replacement of the tube into the posterior chamber due to corneal endothelial cell loss. Postoperative complications were rare: hypotony with athalamia occurred in 1 eye (8.3\%); one patient had a cystic bleb (8.3\%); a hypertensive phase during the first 3 months was present in 9 eyes (75\%) and was controlled temporally with medication. In these cases, the period between AGV implantation and TSCPC was 1.50 years $(0.92 ; 3.00)$, showing no difference from patients in whom this hypertensive phase did not occur $(p=0.206)$.

The median age at TSCPC was 49.50 years $(43 ; 55.75)$, and the period between AGV implantation and TSCPC was 1.63 years (1; 3.65). At baseline, IOP was $24.33 \pm 4.76 \mathrm{~mm} \mathrm{Hg}$, the number of antiglaucomatous medications was $3.92 \pm 0.29$ and logMAR BCVA was $0.34 \pm 0.19$. Median follow-up was 34.50 months (14.50; 50.25). Intraocular pressure values reduced significantly from the first day of postoperative until the last visit, as shown in Figure 2: IOP on the first day was $10.36 \pm 4.13 \mathrm{~mm} \mathrm{Hg}(p<0.001) ; 14.42 \pm$ $4.25 \mathrm{~mm} \mathrm{Hg}$ after 1 month $(p=0.006) ; 15.45 \pm 5.63 \mathrm{~mm} \mathrm{Hg}$ after 3 months $(p=0.012) ; 12.92 \pm 3.40 \mathrm{~mm} \mathrm{Hg}$ after 6 months $(p<0.001)$; and $11.33 \pm 2.90 \mathrm{~mm} \mathrm{Hg}$ at the last visit $(p<0.001)$. The number of antihypertensive medications also decreased to $1.25 \pm 1.42$ $(p<0.001)$. Final logMAR BCVA was $0.39 \pm 0.30(p=0.502)$. Two patients (16.7\%) had a hypertensive phase that was controlled with topical medication. Hypotony did not occur. Exuberant AC reaction, which was defined as the presence of inflammatory cells in AC, happened in 2 eyes (16.7\%); 1 eye had a neurotrophic ulcer (8.3\%), that was well treated and did not compromise final visual acuity. Surgical success was achieved in all cases, 50\% without additional medication (absolute surgical success). There was no need for re-treatment until the last visit.

\section{Discussion}

Numerous studies have reported TSCPC as an effective procedure of lowering IOP in patients with refractory secondary glaucoma. Tekeli and Köse compared the outcomes of micropulsed TSCPC among primary open-angle glaucoma, pseudoexfoliation syndrome, and secondary glaucoma types, referring to worse outcomes, such as a higher retreatment rate in patients with secondary glaucoma. ${ }^{15,16}$

None of those studies evaluated specifically this type of glaucoma. That fact may be explained because FAP is a rare disease, in which the main cluster is located in the north of Portugal. Indeed, the incidence is increasing worldwide, so it is imperative to discuss the best way to manage this condition. Once the ocular involvement is a major characteristic of FAP, these patients need a continuous follow-up in ophthalmology. However, it is important to notice the high mortality of this condition. In our study, two patients (16.7\%) died, which justifies the follow-up not being as long as expected.

Among all ophthalmic manifestations, glaucoma is the major cause of vision loss in these patients. Some predictors were 
previously associated with the onset of glaucoma, particularly the presence of amyloid deposition on the pupil border (scalloped pupil), early onset disease, and previous PPV, all of which are associated with a more severe course of glaucoma. ${ }^{17}$

Although in this review we could not detect these correlations due to its small sample and study design, it is important to notice the early onset of symptoms of our sample-median age was 30.0 years $(22.75 ; 35.0)$-the occurrence of scalloped pupil in 4 eyes (33.3\%) and vitreous amyloidosis in 9 eyes (75.0\%). However, the presence of these features did not seem to influence final IOP or final visual acuity.

There are only a few studies in the literature that show results of surgical procedures in secondary glaucoma related to FAP. Latasiewicz et al. reported the results of non-penetrating deep sclerectomy and Kawaji et al. analyzed the long-term outcomes and complications of trabeculectomy with mitomycin C., ${ }^{9,10}$ Also, a previous study conducted in our department, demonstrated good short-term outcomes of AGV implantation in FAP secondary glaucoma, making it an effective option to treat these cases. ${ }^{12}$ Unfortunately, all these studies presented a small sample and a short follow-up.

No study was carried out to evaluate the results of cycloablative procedures, neither as primary nor secondary treatment options. According to our data, $10.48 \%$ of patients who underwent AGV implantation needed TSCPC to control IOP and none of them needed retreatment. These results seem to be much better than those showed by Kawaji et al., whose $57 \%$ of patients required a second surgical intervention after trabeculectomy, and 33\% more than one reintervention. ${ }^{9}$

Although recent developments improving safety in cyclodestructive procedures, complications may be visionthreatening, such as vision loss, corneal edema, pupillary distortion, cystoid macular edema, choroidal detachment, hypotony, and sympathetic ophthalmia. Indeed, this procedure was classically confined to select cases, such as end-stage, refractory glaucoma, and eyes with poor visual prognosis. Recently, due to advances in laser technology and treatment modalities, TSCPC is considered a viable treatment option in a wider population. ${ }^{15,16,18,19}$ In this study, we only found one case of corneal neurotrophic ulcer and two cases of AC inflammatory reaction, all of them managed without compromising final visual outcomes.

According to existing knowledge and to our center's experience, this type of glaucoma has an early onset, rapid progression, and generally leads to surgical treatment. Our present study shows that AGV implantation is an effective procedure in the management of these patients, once only $10.48 \%$ needed a new surgical procedure (TSCPC), and none of them required retreatment. Among patients who underwent TSCPC, 50\% achieved absolute surgical success, with no need of additional medication to control IOP.

Nevertheless, although the promising results, this is the first study about the use of cycloablative procedures in this type of glaucoma. Recognized limitations include the retrospective design of the study, the small sample, and the follow-up length.

Nowadays, in our referral center, Ahmed valve implantation is the gold-standard surgical procedure to treat patients with glaucoma secondary to FAP, showing good results. For refractory cases, TSCPC seems to be an effective and safe procedure to control IOP. In addition, TSCPC might be an option as a primary therapy in advanced cases. Further studies are necessary to better assess the timing of TSCPC in the surgical treatment of FAP patients.

\section{References}

1. Luigetti M, Romano A, Di Paolantonio A, et al. Diagnosis and treatment of hereditary transthyretin amyloidosis (Hattr) polyneuropathy: current perspectives on improving patient care. Ther Clin Risk Manag 2020;16:109-123. DOI: 10.2147/TCRM.S219979.

2. Planté-Bordeneuve V, Said G. Familial amyloid polyneuropathy. Lancet Neurol 2011;10(12):1086-1097. DOI: 10.1016/S1474-4422(11) 70246-0.

3. Ando Y, Nakamura M, Araki S. Transthyretin-related familial amyloidotic polyneuropathy. Arch Neurol 2005;62(7):1057-1062. DOI: 10.1001/archneur.62.7.1057.

4. Beirão $M$, Matos $E$, Reis $R$, et al. Spatial visual contrast sensitivity in liver transplanted Portuguese familial amyloidotic polyneuropathy (ATTR V30M) patients. Amyloid 2012;19(3):152-155. DOI: 10.3109/13506129.2012.712075.

5. Beirão JM, Malheiro J, Lemos C, et al. Ophthalmological manifestations in hereditary transthyretin (ATTR V30M) carriers: a review of 513 cases. Amyloid 2015;22(2):117-122. DOI: 10.3109/13506129.2015.1015678.

6. Kawaji T, Ando Y, Nakamura M, et al. Transthyretin synthesis in rabbit ciliary pigment epithelium. Exp Eye Res 2005;81(3):306-312. DOI: 10.1016/j.exer.2005.02.003.

7. Martins AC, Rosa AM, Costa E, et al. Ocular manifestations and therapeutic options in patients with familial amyloid polyneuropathy: a systematic review. Biomed Res Int 2015;2015:282405. DOI: 10.1155/2015/282405.

8. Beirão JM, Moreira LM, Oliveira JC, et al. Aqueous humor erythropoietin levels in open-angle glaucoma patients with and without TTR V30M familial amyloid polyneuropathy. Mol Vis 2014;20:970-976.

9. Kawaji $T$, Inoue T, Hara R, et al. Long-term outcomes and complications of trabeculectomy for secondary glaucoma in patients with familial amyloidotic polyneuropathy. PLOS ONE 2014;9(5):1-5. DOI: 10.1371/ journal.pone.0096324.

10. Latasiewicz M, Millá E, Giralt J, et al. Nonpenetrating deep sclerectomy as an effective treatment of glaucoma related to familial amyloid polyneuropathy. J Glaucoma 2015;24(5):e80-e83. DOI: 10.1097/ IJG.0000000000000126.

11. Lee CK, Ma KT, Hong YJ, et al. Long-term clinical outcomes of Ahmed valve implantation in patients with refractory glaucoma. PLoS ONE 2017;12(11):1-13. DOI: 10.1371/journal.pone.0187533.

12. Borges T, Figureiredo A, Reis R, et al. Válvulas de Ahmed em doentes com polineuropatia amiloidótica familiar. Rev Soc Port Oftalmol 2016;39:231-237.

13. Zhang S, Liu C, Liang Y.Diode laser transscleral cyclophotocoagulation as a primary surgical treatment for glaucoma-questions and future. Zhonghua Shiyan Yanke Zazhi/Chinese J Exp Ophthalmol 2016;34:658-662.

14. Bloom PA, Tsai JC, Sharma K, et al. 'Cyclodiode': trans-scleral diode laser cyclophotocoagulation in the treatment of advanced refractory glaucoma. Ophthalmology 1997;104(9):1508-1520. DOI: 10.1016/ s0161-6420(97)30109-2.

15. Tekeli O, Köse HC. Outcomes of micropulse transscleral cyclophotocoagulation in primary open-angle glaucoma, pseudoexfoliation glaucoma, and secondary glaucoma. Eur J Ophthalmol 2020. DOI: 10.1177/1120672120914231.

16. Vig N, Ameen S, Bloom $P$, et al. Micropulse transscleral cyclophotocoagulation: initial results using a reduced energy protocol in refractory glaucoma. Graefe's Arch Clin Exp Ophthalmol 2020;258(5):1073-1079. DOI: 10.1007/s00417-020-04611-0.

17. Beirão NM, Matos ME, Meneres MJ, et al. Vitreous surgery impact in glaucoma development in liver transplanted familial amyloidosis ATTR V30M Portuguese patients. Amyloid 2012;19(3):146-151. DOI: 10.3109/13506129.2012.710669.

18. Vold SD, The Benefits od Transscleral Cyclophotocoagulation, 2012.

19. Douglas E, Gaasterland MD, Reconsidering Transscleral Cyclophotocoagulation, Glaucoma Today 2012. 